\title{
Escola e infância: a transfobia rememorada*
}

\author{
Nosli Melissa de Jesus Bento** \\ Nubea Rodrigues Xavier*** \\ Magda Sarat****
}

\begin{abstract}
Resumo
Apresentamos reflexões sobre os limites da instituição escolar em lidar com crianças e adolescentes que apresentam performances ou comportamentos que fogem às normas binárias de gênero. Os estudos sobre gênero e sexualidade foram lidos a partir da teoria queers e estudos foucaultianos. Como resultados, discutimos os comportamentos, os padrões $e$ as normas que legitimam as infâncias e seus corpos infantis, problematizando os contextos sociais transmisóginos e transfóbicos presentes no espaço escolar, muitas vezes responsável pelo silenciamento desses indivíduos.

Palavras-chave: Crianças Transgêneras, Educação, Infância, Gênero.
\end{abstract}

* Recebido em 14 de junho de 2018, aceito em 17 de setembro de 2019.

** Pedagoga, funcionária administrativa da Secretaria de Estado de Educação de Mato Grosso do Sul/SED, integrante do Grupo Mulheres Transgêneras de MS, em Dourados, MS, Brasil.nosli.nte@gmail.com / http://orcid.org/0000-00030915-3997

*** Professora efetiva da Secretaria de Estado de Educação/SED, integrante do Grupo de Pesquisa Educação e Processo Civilizador/GPEPC/UFGD, em Dourados, MS, Brasil. nubeaxavier@hotmail.com. / http://orcid.org/0000-00015315-6074

**** Professora doutora associada FAED/UFGD, PPGEdu Mestrado/ Doutorado, líder do Grupo de Pesquisa Educação e Processo Civilizador/GPEPC coord. do Laboratório de Práticas e Educação da Infância/LAPEDI, Dourados, MS, Brasil. magdaoliveira@ufgd.edu.br / http://orcid.org/0000-0002-9388-0902 
cadernos pagu(59), 2020:e205911 Escola e Infância: a transfobia rememorada

School and Childhood: Memories of transphobia

\begin{abstract}
In this article we reflect on the limits of school institutions in dealing with children and adolescents who exhibit performances or behaviors that deviate from binary gender norms. We use queers theory and Foucaultian studies to consider gender and sexuality. The paper discusses the behaviors, standards and norms that legitimize childhood and infantile bodies, problematizing the transmisogynous and transphobic social climates found in school spaces, which are often responsible for silencing these individuals
\end{abstract}

Keywords: Transgender Children, Education, Childhood, Gender. 
Aos 11 anos na $5^{\mathrm{a}}$ série, não conseguia mais esconder dos colegas de classe e da escola que eu era afeminado. Passei a ter vergonha do meu nome masculino. Meus colegas, um por um, começaram a se afastar de mim. As chacotas $e$ as agressões começaram! (Marisa)

\section{Introdução}

$\mathrm{Na}$ epígrafe que abre este artigo, temos um exemplo do modo como se expressa a transfobia na escola, isto é, por meio das expressões de violências física, psicológica ou simbólica, bem como por atitudes ou sentimentos negativos em relação às pessoas transgêneras. Seja de modo intencional ou não, tais situações provocam consequências severas (inclusive morte), para quem é discriminado. No relato de nossa entrevistada, percebemos a memória desse tratamento recebido por ela na escola que frequentou na infância.

$\mathrm{O}$ tratamento recebido por Marisa se revela à medida que ela, ou qualquer outra pessoa, foge dos estereótipos legitimados de homens e mulheres pelo sistema binarista de gênero - um sistema que se alimenta da percepção de que meninos não podem parecer "mulherzinha" ou que as meninas não podem parecer um "moleque". Nesse sentido, observamos tratar-se de um "problema" na identidade de gênero e não na orientação sexual desses indivíduos, como em geral se pensa, fazendo com que na escola alunos(as) homossexuais e alunos(as) transgêneros ${ }^{1}$ (as) sofram mais opressões do que os demais. Entendemos que um menino homossexual, por exemplo, se identifica e reivindica como menino; seu desejo e seu afeto se direcionam a outro menino $e$

1 Sobre a pessoa transgênero: "há dois aspectos que cabem na dimensão transgênero, enquanto expressões diferentes da condição. A vivência do gênero como: identidade (o que caracteriza transexuais e travestis); e funcionalidade (representado por crossdressers, dragqueens, drag kings e transformistas)" (Jesus, 2012:7). 
não a alguém do gênero oposto. Já uma menina transgênera, não se identifica com o gênero imposto a ela, de acordo com seu genital (pênis); ela foi designada menino, porém, se reconhece e se reivindica como menina. Tais diferenças entre eles estão na maneira como cada um se identifica, e não em suas sexualidades.

Dito isso, este trabalho surgiu do interesse de pesquisa por essa temática, motivo de estudos, análises, participação acadêmica e política em outras frentes, movimentos sociais que ocupam as pautas cotidianas dos indivíduos que vivem e sobrevivem a esses processos, entre os quais nos incluímos. O objeto de análise contou com relatos de mulheres transgêneras, privilegiando as memórias da infância, que nos mostraram como foram tratadas quando crianças que apresentavam performances de gênero em desacordo com as regras da cisgeneridade compulsória vigente, indicaram os processos de discriminações e/ou violências (físicas, psicológicas e simbólicas) vividas por parte dos alunos, professores, coordenadores e diretores das instituições escolares, que atuaram nas escolas, no período da sua infância. Vale pontuar que estes padrões se repetem com frequência na instituição escolar.

A instituição está pautada por determinados padrões de comportamento e a comunidade escolar não sabe os limites, ou não permite aos alunos ultrapassarem os limites daquilo que está estabelecido e convencionado para o masculino e feminino. É importante discutir, portanto, o conceito de "cisgeneridade" ou o termo "cisgênero" nesse contexto. Tais conceitos surgem como um meio de estabelecer a diferença em relação a "transgênero" ou "transgeneridade". Para Jesus (2012:14), a palavra cisgêneros se define como um termo "guarda-chuva", abrangendo as pessoas que se identificam com o gênero que lhes foi determinado no seu nascimento.

Nesse quadro, a utilização do conceito de cisgeneridade pode funcionar para desestabilizar as normas de gênero tidas como uma verdade universal e imutável, nas quais a identidade de gênero é considerada uma expressão dos cromossomos e dos hormônios. Coloca-se em análise crítica e problematiza a 
normatividade, em vez de se atentar aos corpos tidos como desviantes. Nesses termos, podemos dizer que estamos diante de um conceito-prática de intervenção social criado pelas epistemologias transfeministas.

Assim, organizamos este artigo apontando alguns aspectos fundamentais, ao partirmos da reflexão acerca do padrão de gênero e sexualidade estabelecidos, que continuamente confundem crianças transgêneras com crianças homossexuais. Urge conceituar identidade de gênero e orientação sexual apresentando os estudos do campo e a relevância de entender essas diferenças no sentido de contribuir com a comunidade escolar para diminuir preconceitos que resultam na expulsão de parte desses alunos, mas que também pode ser caracterizada como evasão escolar (Bento, 2011). Tal debate objetiva contribuir com argumentos sustentados em referenciais teóricos como Bento (2006, 2011, 2014), Butler (1997), Foucault (1977), Louro (2000, 2004), Preciado (2013) e outros, que podem dar pistas para a reflexão sobre o tema.

Apresentaremos parte dos dados da pesquisa de campo em que se evidenciaram as violências sofridas por crianças transgêneras no ambiente escolar, apontando que a instituição escolar se expressa como uma das "ferrenhas guardiãs" das normas de gênero (Louro, 2004), constituindo-se, inúmeras vezes, em um ambiente hostil às crianças transgêneras. Todas as entrevistadas nos relataram os preconceitos e/ou violências sofridas e também a negação de seus direitos fundamentais enquanto crianças.

Nesse cenário, nossa metodologia de pesquisa se pautou na história oral, buscando ouvir pessoas que tiveram experiências em seus corpos e memórias pelo fato de serem mulheres transgêneras. Optamos por fazer a pesquisa empírica, a partir de relatos orais e entrevistas com três mulheres, refletindo acerca da condição e da identidade delas, com suas narrativas e memórias. Consideramos especialmente as memórias $e$ as experiências vividas no período da infância e da adolescência. Elegemos esses períodos da vida 
por serem tempos extremamente significativos na formação humana.

$\mathrm{Na}$ infância nos constituímos e nos iniciamos socialmente, pois mais que

um período biológico pelo qual passam todos os indivíduos desde o nascimento, é também uma construção histórica, social e cultural determinada pela organização da sociedade em dado momento histórico(Oliveira, 2008:9).

Portanto, o conceito de infância e a percepção sobre a criança se constituem e se transformam a partir do modo como adultos $e$ crianças se relacionam e expressam tais relacionamentos. Dessa forma, ao elegermos a infância, apresentamos algumas conclusões e reflexões sobre a temática, desejando propor alternativas que possam fazer a escola repensar seu lugar social, e assim abolir de seus espaços padrões e normas cisgêneras hierárquicas, compulsórias e excludentes, que expulsam crianças e adolescentes das instituições.

\section{Identidade de gênero e orientação sexual: conceitos (des)conhecidos}

Gênero é uma construção social, sendo masculino e feminino os possíveis e legitimados pela sociedade. Associa-se gênero a genital e espera-se que haja uma perfeita simetria entre sexo biológico, gênero e orientação sexual, considerada como uma "verdade universal" ou uma "verdade biológica". Ao mesmo tempo que essa simetria produz "corpos perfeitos", ela provoca também exclusão e sofrimento a quem não consegue reproduzir essa lógica que pauta as relações sociais em diferentes grupos e culturas.

Nesse sentido, cada ser humano é único e possui singularidades. Tais características nos assemelham alguns e nos diferenciam de outros, da mesma maneira que os caracteres raciais, sociais, religiosos e outros marcadores que evidenciam a diversidade humana. Nessa lógica, a maneira que uma pessoa se identifica também é diversa, portanto entendemos que identidade 
de gênero está desassociada da orientação sexual. A pesquisadora Jaqueline Gomes de Jesus explica:

Gênero com o qual uma pessoa se identifica, que pode ou não concordar com o gênero que lhe foi atribuído quando de seu nascimento. Diferente da sexualidade da pessoa. Identidade de gênero e orientação sexual são dimensões diferentes e que não se confundem. Pessoas transexuais podem ser heterossexuais, lésbicas, gays ou bissexuais, tanto quanto as pessoas cisgênero (Jesus, 2012:15).

A partir desse contexto diverso, podemos dizer que pessoas travestis $e$ transexuais reivindicam identidades que não se adéquam às normas impostas $e$, por isso, são continuamente punidas. Os grupos sociais dos quais esses indivíduos fazem parte, segundo Berenice Bento (2011), exigem uma linearidade entre o genital $e$ a identidade de gênero, impondo uma complementaridade dos gêneros referenciada na heterossexualidade. No entanto, os seres humanos são diversos, logo, a transgeneridade denuncia a fragilidade dessas normas sociais impostas, pois:

[...] as experiências de trânsito entre os gêneros demonstram que não somos predestinados a cumprir os desejos de nossas estruturas corpóreas. O sistema não consegue a unidade desejada. Há corpos que escapam ao processo de produção dos gêneros inteligíveis e, ao fazê-lo, se põem em risco porque desobedeceram às normas de gênero. Ao mesmo tempo que revela possibilidades de transformações delas (Bento, 2011:551).

Tais características impostas para o masculino e o feminino, ao mesmo tempo em que demarcam as desigualdades de gênero, criam normas que hierarquizam os sexos, com o masculino dominante e o feminino dominado. Nesse ambiente, um menino que se identifica como menina ou uma menina que se identifica como menino é percebido(a) como uma ameaça à ordem 
"natural". Logo, são considerados corpos com comportamentos desviantes, que escapam da hierarquização estabelecida e devem ser corrigidos sob pena de serem marginalizados posteriormente.

Desse modo, mantêm-se os jogos de poder que controlam os corpos e suas identidades. Um controle exercido sem que nos apercebamos, pois são sutis e vistos como uma verdade prédiscursiva, ou seja, inata. Entretanto, mesmo sendo alvo da mais meticulosa, continuada e intensa vigilância $e$ do diligente investimento, há corpos que resistem e denunciam a precariedade da norma estabelecida (Louro, 2000). Sobre essa questão, a autora Letícia Lanz (2014:66) alega:

[...] mesmo que sujeitas às sanções, punições, proibições $e$ interdições que as obrigam a viver à margem da sociedade, mesmo que se tenha que arriscar tudo - família, status, reputação - muitas pessoas "deixam seus armários", se arriscam a transpor as muralhas de gênero, tornando-se assim, transgressores de gênero.

À vista desse quadro opressivo, muitos indivíduos considerados transgressores de gênero são alijados de um pertencimento anterior e rechaçados em seus espaços sociais nas relações familiares e escolares. Assim, sem família, sem acesso a uma educação inclusiva, sem emprego ou outras formas de sobrevivência, se envolvem em ações também condenáveis pelo grupo social, tais como a prostituição, as drogas, a contravenção. Portanto, em muitos casos, essa se torna a única forma de prover o sustento, mesmo que expostos a situações de vulnerabilidade social e ao julgamento social de seus atos por não corresponderem às expectativas criadas.

Outro conceito fundamental, para continuar essa reflexão, diz respeito à orientação sexual que é parte do campo da sexualidade. Diz respeito a afeto, tesão, desejo, lugar para onde sua 'bússola' aponta quando você pensa em alguém com quem poderia se envolver afetivo/sexualmente. Jaqueline Jesus (2012:16) afirma que é 
atração afetivo-sexual por alguém. Sexualidade. Diferente do senso pessoal de pertencer a algum gênero. Os seres humanos podem se interessar pelo sexo oposto e serão heterossexuais. Agora se o interesse for por pessoas do mesmo sexo, serão homossexuais, ou ainda podem se interessar por ambos e serão bissexuais.

No entanto, como afirma Bento (2006), a cultura e a civilização ocidental, herdeiras da moral judaico-cristã, preconizam que nessa sociedade o desejo sexual só poderá existir de fato se estiver relacionado ao casamento, e deverá obedecer a um destino estabelecido (apaixonar-se, casar-se e reproduzir-se). Esse destino imposto é viável apenas pelo viés da heterossexualidade, que é considerada pelo cânone cristão a única forma correta, aceita, sagrada, natural e inquestionável. Assim, aprendemos desde o nascimento que as relações afetivas/sexuais só serão consideradas naturais ou normais se acontecer entre pessoas do sexo oposto, ou seja, entre um homem e uma mulher.

Nesse quadro histórico, quem sente um forte sentimento de afeto, amor, desejo por alguém do mesmo sexo sentirá a força da opressão das instituições reguladoras (família, escola, Igreja etc.), que condenarão tal atitude como imoral, pecadora, doentia, sendo esse indivíduo, muitas vezes, afastado dos convívios familiar e social.

Segundo Butler (1997), a heterossexualidade compulsória teme a homossexualidade que, mesmo não sendo mais considerada uma patologia pela ciência médica, socialmente é julgada como uma "ameaça contagiosa". Ela é temida e vista como uma rebelião às normas. Dessa forma, torna-se imperioso agir para corrigir essa sexualidade desviante e, para tanto, o corpo rebelde deverá ser domesticado, ou seja, deverá ser produzido socialmente.

A produção de um corpo dócil será possível somente através de uma distribuição desse corpo no espaço normativo da sociedade (Foucault, 1977). Ela nos impõe padrões de sexualidade e nós internalizamos tais valores, que estão condicionados ao 
padrão hegemônico. Aos corpos que não se submetem resta a discriminação. E na escola não é diferente. Ela atua de forma a disciplinar, produzir corpos dóceis que aceitem regras e a ordem social (Foucault, 1977). A educação, segundo o autor, tratou de ajustar e enquadrar crianças em padrões de ser, agir, pensar.

Tal contexto faz com que muitas pessoas homossexuais se escondam, reprimindo seus sentimentos $e$ temendo as consequentes represálias. Em razão da opressão, muitos homossexuais desenvolvem baixa autoestima, tornam-se melancólicos, apresentam quadros depressivos, e muitas vezes são incapazes de medidas afirmativas para construção da sua cidadania. Sentem-se desvalorizados, negam seus desejos para si mesmos e para os outros, se autoflagelam psíquica e fisicamente e, em muitos casos, cometem suicídios. Nesses quadros teóricos do debate, precisamos chegar ao espaço escolar para fomentar a reflexão, a informação e garantir um espaço de aprendizagem social de conceitos que são fundamentais para avançar e garantir o direito social de todas as crianças e adolescentes, bem como toda a comunidade escolar.

Gênero e sexualidade na escola: disciplinas e conteúdos de aprendizagem

O enfrentamento da transfobia escolar precisa ser um debate que percorra os caminhos da educação começando pela escola, lugar e espaço no qual, desde a primeira infância, a criança fica por muito tempo. Esse lugar precisa discutir os modelos discriminatórios, fomentar a reflexão, ensinar o respeito e a aceitação às identidades de gênero divergentes.

Como uma disciplina escolar, é fundamental que haja um debate que discuta a elaboração de políticas de enfrentamento e a conquista de direitos individuais chancelados pelo campo jurídico, avançando para a criminalização da LGBTfobia, entendida aqui como práticas discriminatórias e violentas contra pessoas gays, lésbicas, bissexuais e transgêneros. Essas discussões, sobretudo, 
contribuir com debates sobre a temática "gênero" dentro dos espaços escolares.

Nossa pesquisa aponta situações que consideramos tratar de temas bastante controversos e polêmicos na atualidade, especialmente se levamos em conta o avanço de movimentos conservadores e fundamentalistas. Porém, o debate é necessário não só para combater a exclusão de crianças e adolescentes LGBTs, como também para a desconstrução das práticas de machismo e misoginia que contribuem para agravar problemas vividos na escola como gravidez precoce e indesejada em meninas jovens, violências de gênero contra mulheres $e$ pessoas transgêneras - temáticas que devem ser inseridas na elaboração de uma proposta de escola inclusiva para crianças e adolescentes; no caso desta pesquisa, especialmente as pessoas transgêneras.

No entanto, enquanto realizamos a pesquisa e atuamos nas escolas, observamos um cenário político cada dia mais inóspito, capitaneado por fundamentalistas de toda ordem, especialmente os religiosos que discorrem sobre assuntos como "ideologia de gênero" sem nenhum conhecimento credenciado sobre a temática. Percebemos a retirada desse debate nos planos de educação em municípios e estados brasileiros, revelando que a laicidade do Estado só existe na teoria.

Se por um lado, pesquisadores/as e estudiosos/as tentam fomentar essa discussão na escola, buscando soluções $e$ alternativas para dirimir os problemas vividos por crianças $e$ adolescentes, por outro vemos o falso enunciado sobre a "ideologia de gênero", disseminado na sociedade e no ambiente escolar como uma tentativa de destruir o binarismo de gênero. Assim, os "arautos da moralidade" defendem e pautam seu discurso na preservação da família "tradicional" brasileira, que estaria ameaçada pelo debate. Esse discurso com intenção rasa $e$ desonesta de causar pânico moral tem se expressado em diversos espaços sociais sem acesso à informação (Louro, 2000).

Apesar de democracia e laicidade estarem previstas em lei, não é o que se efetiva e concretamente. A legislação define medidas que impedem segmentos religiosos de apontarem 
prerrogativas e ou determinarem políticas educacionais para o Estado brasileiro. Todavia, quando um segmento religioso católico ou evangélico determina quais temáticas devem ser debatidas na escola, privilegiam determinados segmentos em detrimento de outros grupos de orientações religiosas diversas. E, ao permitir tal prerrogativa, estamos outorgando a esses segmentos o direito de decidirem pela sociedade como um todo (Andrade, 2012). O que vemos nesse contexto atual são fundamentalistas religiosos querendo pautar as práticas pedagógicas da escola, na tentativa de alinhar tais práticas educativas ao seu discurso e prática religiosa, no caso, da religião cristã.

Cremos que ao falar de gênero, falamos de ciência. Se a educação é laica, não vemos motivos para não discutir teorias científicas de gênero na escola. Todas as discussões são saudáveis desde que sejam discutidas com respeito, e sabemos que a ciência só consegue avançar quando damos oportunidades para que pessoas com pensamentos contrários ao nosso, tenham oportunidade de escolha, tudo dentro de um processo respeitoso no qual todos conseguem falar e serem ouvidos.

Debater identidade de gênero e orientação sexual se faz necessário porque não recebemos nas escolas apenas alunos cisgêneros e heterossexuais. Recebemos também pessoas transgêneras, homossexuais, bissexuais e lésbicas. Posto isso, não vemos porque não trazer à luz da discussão a realidade desse segmento. Se alunos(as) gays, lésbicas ou transgêneros(as) podem $e$ devem debater temas pertinentes a cisgeneridade $e$ heterossexualidade compulsória- o que é percebido com naturalidade -, não há motivos para não debater temas sobre identidades e sexualidades de pessoas LGBTs.

O contexto do debate é fundamental, pois essas pessoas não vão deixar de existir só porque retiramos tais pautas dos planos educacionais. Toda essa população se relaciona sexualmente, e a educação precisa tratar da questão de modo responsável: falar de sexo, sexualidade, prazer, desejo, também com o foco em saúde, segurança, orientação aos adolescentes sobre doenças sexualmente transmissíveis e gravidez precoce decorrentes de uma 
vida sexual não saudável. Há ainda, e não menos graves, os problemas afetivos e psicológicos de pertencimento, aceitação, respeito, direitos sociais. Negar esse debate é negar às pessoas espaços saudáveis de convivência e automaticamente expor crianças e adolescentes à situação de vulnerabilidade social.

Quando a Constituição Federal (1988), em seu artigo 1 inciso III, estabelece que a dignidade da pessoa humana deve ser preservada, não se excetuam pessoas LGBTs. Logo, o poder público tem a obrigatoriedade legal de providenciar a essa população um tratamento digno como sujeitos de direitos que são. Nenhuma instituição deveria proibir às pessoas heterocisgêneras o debate sobre gênero e sexualidade de pessoas LGBTs, pois no âmbito escolar estaremos nos relacionando não apenas com aluno transexual, mas talvez com uma agente de portaria lésbica, uma merendeira travesti etc. Tais indivíduos fazem parte dos grupos sociais dos quais todos pertencemos.

Assim, a pesquisa nos indica que a possibilidade de debater gênero é diferente de se impor gênero, que falar de transgeneridade não é pernicioso e não nos "contaminamos por osmose" (Bento, 2006). Partindo dessa perspectiva, as pessoas heterocisgêneras precisam ter conhecimento, ter a formação que as faça entender o quanto é importante a escola fomentar as reflexões. Negar o debate é invisibilizar as pessoas e permitir que sejam sempre vistas como o "outro". Assim, o diferente é o "outro" e este, como aponta (Louro, 2004), é sempre o "patologizado" e o "anormal". Somente o conhecimento sobre a temática vai permitir mudar essas concepções fechadas $e$ discriminatórias, e a escola tem grande responsabilidade como espaço de formação na infância de todos esses grupos sociais.

\section{Cotidiano escolar: lugar onde a transfobia é expressa e se traduz}

A escola é um espaço plural, e nela circulam indivíduos que trazem dentro de si características únicas e heterogêneas. Temos ali uma diversidade enorme de identidades racial, religiosa, étnica, de classe social, e também uma diversidade de identidade de 
cadernos pagu(59), 2020:e205911 Escola e Infância: a transfobia rememorada

gênero e orientação sexual. É função da comunidade escolar preparar seus alunos(as) para viverem coletivamente e respeitarem toda essa pluralidade. Entendemos que o objetivo principal da escola não é apenas socializar o conhecimento, mas promover condições necessárias para a formação intelectual e moral dos seus alunos(as), e o resultado desse esforço é que promove o pleno desenvolvimento do indivíduo como cidadão. No entanto, em relação às identidades divergentes de gênero, a escola, infelizmente, não está preparada e não fomenta medidas afirmativas para administrar os possíveis conflitos que podem ocorrer dentro dos seus espaços.

Crianças $e$ adolescentes transgêneros - em especial as meninas - sofrem com a transfobia praticada pelos outros alunos no cotidiano escolar, por vezes longe dos olhos dos adultos. Transgredir as normas de gêneros torna-se uma condição sine qua non para que essas crianças sejam alijadas dos círculos de amizade que se constituem nesse espaço, $e$ os amigos são fundamentais para criar nesses momentos um sentimento de pertença social a um grupo específico. Sobre isso, uma das nossas entrevistadas relata:

\begin{abstract}
Perdi meu amigo protetor! Zé Carlos era meu melhor amigo antes de começar a me transicionar, ele me defendia nas brigas. Mas passou a se posicionar ao lado dos mais "fortes". Alinhou-se ao lado dos pequenos machos quando eles tornaram a minha vida um inferno humano! Até meu irmão, que era de outra sala $\left(7^{\mathrm{a}}\right.$ série), desistiu. Não aguentou as chacotas. Riam dele porque era irmão de "viado", de "marica". Minha vida se tornou então, humanamente infernal! (Marisa).
\end{abstract}

No fragmento da história lembrada por Marisa, podemos perceber as manifestações do que chamaríamos de bullying ${ }^{2}$ transfóbico,

2 Bullying é um termo inglês que se origina da palavra bully, que significa brigão, valentão, tirano, e designa comportamentos agressivos, antissociais, repetitivos e intencionais, praticados por uma ou mais pessoas. Caracteriza-se por atitudes 
que aparece mais potencializado em relação aos meninos, em decorrência de processos de formação dentro de padrões $e$ normas machistas e sexistas que exigem um tipo de comportamento específico. No grupo social em que vivemos, muitas vezes a norma em geral se remete ao modelo do "homem branco, heterossexual, de classe média urbana e cristão" e essa passa a ser a referência que não precisa mais ser nomeada. Sendo esse o modelo, todos os demais indivíduos que transgridam essa regra serão os "outros" sujeitos sociais que se tornarão "marcados", que se definirão e serão denominados a partir dessa referência (Louro, 2000). Nas memórias de Marisa verificamos tal situação.

Nesse contexto, os meninos aprendem que as meninas transgêneras são aquelas de quem se deve manter distância, não podendo namorá-las nem participar dos mesmos grupos de trabalho; elas precisam ser evitadas na convivência cotidiana em todas as atividades dentro e fora da escola. No espaço escolar, se um menino cisgênero brinca com uma menina transgênera no recreio, torna-se vítima de chacota; seu status de macho estará "ameaçado" durante todo o ano letivo. Desse modo, os meninos preferem se afastar e acompanhar aqueles que vão discriminá-la. Tal exclusão incide na vida dessas meninas, contribuindo para perpetuar o status de criaturas abjetas (Bento; Pelúcio, 2012), provocando efeitos devastadores na autoestima delas, segundo relato:

Zé Carlos nunca mais veio comigo para escola, nunca mais sentou comigo e nem me cumprimentava mais. Percebi que ele sentia vergonha de mim e que me culpava por eu ter "virado uma mariquinha". Era assim que ele falava! Logo comecei a permanecer todo o recreio dentro da sala de aula. As agressões passaram do campo das palavras para o físico. Em minhas tentativas de revide, eu levava tapas,

ofensivas, intimidação, humilhação, constrangimento, isolamento, exclusão, difamação, agressão física e/ou verbal até mesmo furtos, e está presente nas escolas. Muitas delas, no entanto, negam esse tipo de comportamento em suas dependências e imediações (Fante, 2005). 
socos e pontapés. Zé Carlos, embora se juntasse aos outros para zombar de mim, curiosamente não me agredia. Mas os outros garotos sim, e ele não fazia nada para impedir. Quando eu passava pelo corredor, próximo ao grupinho dos "machos", além de um 'E aí, viadinho?', eu levava sempre uns tapas, e sempre havia algum engraçadinho para sair rebolando atrás de mim. Eu nunca os olhava nos olhos. Sentia muita vergonha! (Marisa).

A escola não só potencializa essa situação discriminadora, mas avaliza as performances convencionais dos códigos da superioridade masculina, ou seja, no menino o comportamento agressivo e viril, e, nas meninas, a submissão e a aceitação. Além disso, a escola também vigia o corpo e os comportamentos, indicando que precisam internalizar as normas hierárquicas de gênero. Os que são dissidentes desses modos convencionados socialmente, a escola e o grupo castigam. Crianças e adolescentes não aprendem na escola que existem identidades transgressoras a tais normas e que deveriam ser aceitas. O que ocorre é o contrário: essas pessoas são rejeitadas.

Os meninos têm uma maldade que eu não entendo! Todos os dias escreviam no quadro meu apelido: "Claudemir viadinho" ou "Claudemir mariquinha". Eu odeio esse nome! A situação de bullying era clara. Eu sofria muito, não tinha como não sofrer! Quando cruzavam comigo, riam e imitavam meus trejeitos femininos. Alguns meninos da sala não me tocavam. Ouvia eles dizerem que, caso isso ocorresse, pegariam "viadice". Isso tudo era muito dolorido para mim! (Karina).

Mais um exemplo do modo como a constituição do modelo e do padrão heteronormativo se expressa na escola, especialmente considerando a relação dos meninos com as meninas transgêneras. No caso contrário, em relação às meninas, a face da transfobia se modifica e não é tão explícita; ela é praticada sutilmente, um preconceito velado ou dissimulado, e difere das atitudes violentas dos meninos. Provavelmente devido à forma 
como são socializadas em uma situação de opressão, na qual a hierarquia dos gêneros se faz evidente muito mais no caso masculino do que feminino, embora esta última não seja menos real.

Com as meninas não tive muitos problemas, a maioria gostava de mim. Dividíamos o lanche do recreio, me chamavam de Karina, trocávamos figurinhas dos álbuns da Disney. Ensaiávamos coreografia de danças. Fazíamos tarefas juntas. Mas sempre aparecia um menino para perturbar a gente e rir delas porque elas andavam comigo. Eram poucas as que me discriminavam. Mas era um preconceito velado. Não me xingavam ou me batiam, mas me evitavam. Se eu chegava na rodinha, elas saíam. Um dia perguntei para uma delas por que ela não falava comigo, já que nunca tinha feito nada para ela. Ela me disse que sua mãe falou que, se ela conversasse ou andasse comigo, ela iria apanhar! (Karina).

Os meninos, em geral, são socializados para serem mais rebeldes, ativos, viris, e socialmente é esse o perfil de gênero que se espera. Assim, a transfobia praticada por eles torna-se mais violenta e incisiva. Já as meninas são ensinadas a serem contidas, dóceis, amáveis, aprendem a ser mais "respeitáveis". Nesse caso, a expressão da transfobia por parte delas é mais velada e sutil. Mesmo na discussão acerca do sexismo sendo levada para a escola, ainda ouvimos muito dos pais, mães e professores/as que "meninas são melhores nisso" ou "meninos são melhores naquilo", ou "as meninas são mais caprichosas" e "meninos mais relaxados" - características que qualificam e categorizam as atitudes das crianças de forma dicotômica. Nessa hierarquia de gênero, prevalece o masculino que goza de privilégios negados ao gênero feminino, refletindo nas formas sutis a discriminação $e$ preconceito praticados contra meninas transgêneras (Louro, 2000).

A educação tem um discurso inclusivo, mas na prática nega a possibilidade da existência do outro. A produção da alteridade como algo fora da normalidade não é bem vista, entretanto, é 
cadernos pagu(59), 2020:e205911 Escola e Infância: a transfobia rememorada

fundamental a aceitação do outro para garantir seu autorreconhecimento como indivíduo pertencente a um grupo (Britzman, 2002). Na escola, adolescentes transgêneros, na maioria das vezes, não podem contar com a proteção dos agentes escolares que deveriam protegê-las como os demais. Guacira Louro (2004) aponta que o corpo queer é um corpo estranho, que incomoda e gera desconfortos, por isso professores/as $e$ gestores/as não sabem lidar com tais diferenças. Nas memórias de uma das nossas entrevistadas, essa situação se expressa de modo contundente:

Um dia um menino me xingou de viado feio e me bateu no recreio; me deu um soco no nariz e o sangue escorreu, me sujei toda de sangue. Fomos parar na diretoria. O garoto foi suspenso. A diretora, antes de me levar ao Posto de Saúde mais próximo, virou para mim "possessa de raiva" e disse: "Se você parasse de 'fingir' que era menina, isso não teria acontecido"(Karina).

Esse fragmento indica a premissa do não saber lidar com o "corpo estranho do outro", conforme apontado por Britzman e Louro, mostrando um discurso e uma prática que culpabilizam a própria criança e/ou o adolescente pelas violências sofridas. Para Berenice Bento (2006, 2011), as crianças e adolescentes transgêneros sofrem nas escolas uma verdadeira tortura psicológica, portanto na idade adulta é muito comum encontrar muitas mulheres transgenêras analfabetas. Essa autora aponta, ainda, que a estrutura chamada "escola" tem em sua constituição algo que nega, silencia $e$ faz esses corpos tornarem-se inadequados, insuportáveis e repulsivos para o espaço escolar.

$\mathrm{Na}$ memória da nossa entrevistada Marisa, percebemos a reprodução desses comportamentos de forma concreta na postura da diretora, sendo que a gestora deveria ser a pessoa credenciada para atuar de forma educativa e acolhedora, procurando uma

3 "Queer pode ser traduzido por estranho, talvez ridículo, excêntrico, raro, extraordinário", diz Louro (2004:38). 
intervenção positiva e formas de inibir/coibir comportamentos discriminatórios.

Os professores nunca tomaram nenhuma atitude. Quase todos os dias, eu voltava para casa machucada. Cansada daquilo tudo, um dia reagi e bati num menino. A diretora chamou a minha mãe. Lembro dela dizendo que eu tumultuava a escola com meu jeito. Disse que eu estava me tornando perigosa, porque agredi o menino, que era para ela tomar providência. Ela não disse nenhuma palavra sobre as agressões que eu sofria, nem ela $e$ nem as professoras! Nenhuma palavra ao menino que xingou! Tentei explicar que bati no menino porque estava cansada de ouvir xingamentos. A diretora disse que eu apanhava porque insistia em ser afeminado, ficava imitando as meninas e isso perturbava os meninos. Segundo ela, o dia que eu não ia para escola, ela não tinha nenhuma reclamação dos meninos. Dentro da sala de aula, eu estava a salvo deles, mas lá fora ou no recreio era aquele inferno. Decidi não sair mais no recreio (Marisa).

Essa memória da infância escolar de Marisa mostra, de forma evidente, o despreparo dos docentes e da gestão em lidar com as diferenças de identidades de gênero. Tal falta de formação se dá em decorrência da falta de informação e da discussão sobre a temática nos cursos de formação de professores - as licenciaturas não têm conteúdos que se reportam a temas que são relevantes na formação docente. Nesse aspecto, é urgente o Estado brasileiro discutir essa oferta de cursos de capacitação em disciplinas de licenciatura, não somente na formação inicial, mas também na formação continuada, para aqueles que atuam na educação em todos os níveis.

A reflexão, o estudo e a pesquisa são essenciais na mudança de atitude, bem como a discussão de políticas que permita 
apontar perspectivas a serem trabalhadas dentro da escola, onde a norma, em geral, é um processo de naturalização do cissexismo. ${ }^{4}$

A escola, historicamente, vem tratando a questão de modo a diagnosticar $e$ inserir esses corpos transgressores, mas num movimento de apontar valores salvacionistas, no intuito de conduzi-los para uma vida melhor. A intenção de proteger, de salvar, de conduzir ao caminho da conversão dos modos provoca medo, opressão, exclusão e até mesmo a morte (Preciado, 2013), pois a escola recebe o indivíduo desde muito cedo e é responsável pela formação da criança e do adolescente por ser um espaço de aprendizagem e de socialização dos grupos humanos.

Finalmente, a escola necessita ser um lugar seguro, que assuma a função de repensar os valores sociais impostos, reveja $e$ discuta critérios excludentes para tornar-se espaço de produção de novos conhecimentos, levando seus quadros a refletir sobre as consequências da prática do que Berenice Bento (2011) chama de "heteroterrorismo" - quando as práticas e os enunciados incentivam ou inibem comportamentos a cada insulto ou piada homofóbica. Para a autora, se um menino gosta de brincar de boneca, as afirmações: "Pare com isso! Isso não é coisa de menino!", ou reiterações do/a pai/mãe ou professor/a do tipo "menino não chora!", "comporte-se como menina!", "isso é coisa de bicha!", fazem com que a "subjetividade daquele que é o objeto dessas reiterações é[seja] minada" (Bento, 2011:52). E assim, a própria escola - aquela que deveria adotar uma pedagogia libertadora e democrática, com perspectivas aproximadas às noções de cuidado de si e de práticas de inclusão distantes de um enquadramento moralista -, apresenta-se como lugar de exclusão.

No cotidiano das escolas em que estudaram nossas entrevistadas, percebemos, a partir de seus relatos, as condições adversas vividas na infância: as violências sofridas e expressas

${ }^{4}$ De acordo com Bagagli (2017), a designação de cissexismo é baseada em crenças de que os gêneros, as vivências $e$ as questões políticas das pessoas transgêneras sejam menos verdadeiras e legítimas do que de pessoas cisgêneras. 
física, emocional e psicologicamente em todos os limites da instituição, e as memórias das condições de insegurança, da restrição de liberdade representada pelo medo de sair para o recreio, as críticas ao modo de vestir, de caminhar, de se comportar, enfim, uma série de atos discriminatórios praticados pelos(as) alunos(as), docentes e todas as pessoas envolvidas na instituição.

As meninas transgêneras, quando externalizaram suas identidades de gênero femininas no contexto escolar, colocaramse em situação de vulnerabilidade dentro do grupo social a que pertencem, pois os direitos da criança queer ainda são desconhecidos em espaços em um modo onde a norma prevalece. Portanto, a escola e os grupos nos quais essas crianças se inserem precisam aprender e ensiná-las a crescerem em um lugar no qual a violência sexual ou de gênero seja banida (Preciado, 2013). As crianças queer necessitam da validação de seus direitos à livre autodeterminação de gênero $e$ de sexualidade, assim como as crianças heterossexuais e cisgêneras. A partir de uma percepção de políticas inclusivas, a perspectiva de compreensão desses conceitos é fundamental, e só poderemos discutir o problema da transfobia institucionalizada dentro da escola quando, institucionalmente, nas esferas legislativas e educativas, começarmos a pautar essa temática, desde a infância e em todos os espaços das crianças e adolescentes.

\section{Parando por ora, mas seguindo com a reflexão}

As nossas pesquisas evidenciam que meninos(as) transgêneros(as) estão sendo expulsos(as) de casa muito cedo, ficando fora da escola e do respaldo de seus direitos e de sua cidadania. Porém, tanto a família como a escola são responsáveis por eles. Assim, são necessárias medidas como recolocar em debate, de imediato, as orientações dos Parâmetros Curriculares Nacionais, que afirmam que "o conceito de gênero diz respeito ao conjunto das representações culturais e sociais" (PCN, 1997:98). Os PCNs devem ser utilizados nos debates, não somente em sala de 
aula, mas em parceria com as famílias, no intuito de promover mudanças dos conceitos acerca de gênero, sexualidade e temas pertinentes a essa questão.

A perspectiva de uma ampliação do debate é fundamental na proposição e na adoção, por parte do Estado brasileiro, de políticas educacionais promotoras de campanhas afirmativas dentro das escolas, com a utilização de práticas pedagógicas como cartilhas, documentários, seminários, palestras, curtas-metragens, filmes, entre outros. Além dessas, a proposição de realização de cursos de capacitação para os profissionais da educação (docentes, funcionários(as), gestoras/gestores) e para a comunidade escolar (estudantes e famílias), abordando temas sobre direitos humanos, sexualidades e gênero, incluindo nesse debate o cotidiano institucional.

Tais medidas afirmativas têm sido efetuadas, mas ainda de forma tímida e incipiente. É necessário que o Estado assuma as legislações e compromissos dos quais é signatário, entre eles, a Declaração de Direitos Humanos. Ao assinar, este documento, o Brasil se comprometeu a cumprir e respeitar essa declaração, garantindo o que diz em seu primeiro artigo:

Todas as pessoas nascem livres $e$ iguais em dignidade $e$ direitos. São dotadas de razão e consciência e devem agir em relação umas às outras com espírito de fraternidade(Declaração dos Direitos Humanos, Art. I.).

O aparato legal normatiza a educação em vários níveis na tentativa de promover as garantias individuais, tanto na educação infantil como nos primeiros anos do ensino fundamental, sendo imprescindível difundir conceitos de respeito à diversidade sexual, de gênero, e ressaltar aspectos como a cultura e a história, de modo a dissociar esses conceitos de um pretenso "destino biológico".

Outra perspectiva que a pesquisa permitiu perceber foi a importância de parcerias com os movimentos sociais $e$ as organizações não governamentais/ONGs na promoção de políticas 
públicas. Tais parcerias promovem redes de apoio, fomentam debates producentes $e$ oferecem recursos para a mediação de conflitos no atendimento as pessoas que passam por essa situação. A tarefa não é fácil, como a escola quer crer, mas é desafiadora $e$ nos instiga a questionar o problema da transfobia escolar, a reivindicar respeito às pessoas transgêneras reconhecendo-as como sujeitos de direitos.

Finalizamos nos reportando à nossa bibliografia: ela nos ensinou que as pessoas têm o direito de serem livres, de existirem de fato, e que suas identidades de gênero divergentes podem deixara categoria diagnóstica e passar uma categoria política, de resistência; e que podemos almejar uma instituição educativa mais sensível, preocupada com a singularidade dos(as) aluno(as) em lugar de mantermos uma instituição excludente. Desejamos uma escola onde seja possível ser criança e adolescente, fomentando uma multiplicidade de processos de subjetivação, lugar no qual Marisas, Gabrieles e Karinas não sofram discriminações $e$ violências e possam seguir vivendo as suas infâncias como quaisquer outras.

\section{Referências bibliográficas}

BAGAGLI, P. Beatriz. Orientação sexual na identidade de gênero a partir da crítica da heterossexualidade e cisgeneridade como normas. Periódicos UNIFAP, v. 7, n. 1, Macapá, $1^{\circ}$ semestre, 2017 [https://periodicos.unifap.br/index.php/letras/article/view/3073 - acesso em 10 out. 2020]. DOI: http://dx.doi.org/10.18468/letras.2017v7n1.p137-164

BENTO, Berenice. A reinvenção do corpo: sexualidade e gênero na experiência transexual. Rio de Janeiro,Garamond, 2006.

BENTO, Berenice. Na escola se aprende que a diferença faz a diferença. Revista Estudos Feministas, v. 19, n. 2, Florianópolis, 2011, pp.549559 [http://www.scielo.br/scielo.php?script=sci_arttext\&pid=S0104026X2011000200016\&lng=en\&nrm =iso].

DOI http://dx.doi.org/10.1590/S0104-026X2011000200016

BENTO, Berenice. Brincar de gênero: uma entrevista com Berenice Bento. cadernos pagu(43), Campinas, Núcleo de Estudos de Gênero- 
cadernos pagu(59), 2020:e205911 Escola e Infância: a transfobia rememorada

Pagu/Unicamp,

jul./dez.

2014

[http://www.scielo.br/scielo.php?script=sci_arttext\&pid=S0104-

$83332014000200475 \& \operatorname{lng}=\mathrm{pt} \& \mathrm{nrm}=$ iso].

DOI https://doi.org/10.1590/0104-8333201400430475.

BENTO, Nosli Cesar de Jesus. Infâncias transgêneras: relatos de sobrevivência. Monografia (Graduação em Pedagogia), Universidade Federal da Grande Dourados, Dourados, 2018.

BRASIL. Constituição (1988). Constituição da República Federativa do Brasil. Art. 08. Brasília, DF, Senado, 1988.

BRASIL. Secretaria de Educação Fundamental. Parâmetros Curriculares Nacionais: pluralidade cultural e orientação sexual, v.10.Brasília,MECSEF, 1997.

BRASIL. Secretaria de Educação Fundamental. Referencial Curricular Nacional para a Educação Infantil: formação pessoal e social, v. 2. Brasília, MECSEF, 1998.

BRITZMAN, Deborah P. Sexualidades transgressoras: una antologia de estudios queer. Barcelona, Içaria, 2002,pp.197-228.

BuTLER, Judith. A vida psíquica do poder: teorias da sujeição. Standford, CA, Standford University Press, 1997.

FouCAUlT, Michel. Vigiar e punir: nascimento da prisão. Petrópolis, RJ, Vozes, 1977.Tradução: Ligia M. Ponde Vassalho.

JESUS, G. J. Orientaçôes sobre identidade de gênero: conceitos e termos. Brasília, Fundação Biblioteca Nacional, 2012.

LANZ, Letícia. O corpo da roupa: a pessoa transgênera entre a transgressão e a conformidade com as normas de gênero. Dissertação (Mestrado em Sociologia), Universidade Federal do Paraná, Curitiba, 2014.

LOURO, Guacira Lopes. O corpo educado: pedagogias da sexualidade. Belo Horizonte, Autêntica, 2000.

LOURO, Guacira Lopes. Um corpo estranho: ensaios sobre sexualidade e teoria queer. Belo Horizonte, Autêntica, 2004.

ONU. Declaração Universal dos Direitos Humanos. Site da Organização das Nações Unidas [http://www.onu- 
brasil.org.br/documentos_direitoshumanos.php -acesso em 25 mar. 2018].

PRECIADO, Beatriz. Quem defende a criança queer. Transfeminismo, 2013. [http://transfeminismo.com/2013/01/24/-Quem-defende-acriança-queer/ - acesso em 20 set. 2017]. 